Article

\title{
Human Papillomavirus Genotype Distribution in Invasive Cervical Cancer in Pakistan
}

\author{
Asif Loya ${ }^{1,+}$, Beatriz Serrano ${ }^{2,+}$, Farah Rasheed ${ }^{3}$, Sara Tous ${ }^{2}$, Mariam Hassan ${ }^{3}$, Omar Clavero ${ }^{2}$, \\ Muhammad Raza ${ }^{1}$, Silvia De Sanjosé ${ }^{4}$, F. Xavier Bosch ${ }^{2}$ and Laia Alemany ${ }^{4, *}$ \\ 1 Department of Pathology, Shaukat Khanum Memorial Cancer Hospital and Research Centre Lahore, \\ Punjab 54000, Pakistan; asifloya@skm.org.pk (A.L.); drrazamuhammadi@gmail.com (M.R.) \\ 2 Unit of Infections and Cancer (UNIC), Cancer Epidemiology Research Programme, Catalan Institute of \\ Oncology (ICO)-IDIBELL, L'Hospitalet de Llobregat, Gran Via de l'Hospitalet, 199-203, 08908 L'Hospitalet \\ de Llobregat, Barcelona, Spain; bscarro@iconcologia.net (B.S.); stous@iconcologia.net (S.T.); \\ oclavero@iconcologia.net (O.C.); x.bosch@iconcologia.net (F.X.B.) \\ 3 Clinical Research Office, Shaukat Khanum Memorial Cancer Hospital and Research Centre Lahore, \\ Punjab 54000, Pakistan; crc3@skm.org.pk (F.R.); crc@skm.org.pk (M.H.) \\ 4 Unit of Infections and Cancer (UNIC), Cancer Epidemiology Research Programme, Catalan Institute of \\ Oncology (ICO)-IDIBELL, L'Hospitalet de Llobregat, Gran Via de l'Hospitalet, 199-203, 08908 L'Hospitalet \\ de Llobregat, Barcelona, Spain; CIBER Epidemiología y Salud Pública (CIBERESP). Madrid, Spain; \\ s.sanjose@iconcologia.net \\ * Correspondence: lalemany@iconcologia.net; Tel.: +34-93-2607812 \\ + These authors contributed equally to this work.
}

Academic Editor: Samuel Mok

Received: 31 May 2016; Accepted: 26 July 2016; Published: 30 July 2016

\begin{abstract}
Few studies have assessed the burden of human papillomavirus (HPV) infection in Pakistan. We aim to provide specific information on HPV-type distribution in invasive cervical cancer (ICC) in the country. A total of 280 formalin-fixed paraffin-embedded tissue blocks were consecutively selected from Shaukat Khanum Memorial Cancer Hospital and Research Centre (Lahore, Pakistan). HPV-DNA was detected by SPF10 broad-spectrum PCR followed by DNA enzyme immunoassay and genotyping by LiPA25. HPV-DNA prevalence was 87.5\% (95\%CI: 83.0-91.1), with $96.1 \%$ of cases histologically classified as squamous cell carcinoma. Most of the HPV-DNA positive cases presented single infections (95.9\%). HPV16 was the most common type followed by HPV18 and 45. Among HPV-DNA positive, a significantly higher contribution of HPV16/18 was detected in Pakistan (78.4\%; 72.7-83.3), compared to Asia (71.6\%; 69.9-73.4) and worldwide (70.8\%; 69.9-71.8) and a lower contribution of HPVs31/33/45/52/58 (11.1\%; 7.9-15.7 vs. $19.8 \%$; $18.3-21.3$ and $18.5 \%$; 17.7-19.3). HPV18 or HPV45 positive ICC cases were significantly younger than cases infected by HPV16 (mean age: 43.3, 44.4, 50.5 years, respectively). A routine cervical cancer screening and HPV vaccination program does not yet exist in Pakistan; however, the country could benefit from national integrated efforts for cervical cancer prevention and control. Calculated estimations based on our results show that current HPV vaccine could potentially prevent new ICC cases.
\end{abstract}

Keywords: human papillomavirus; cervical cancer; genotype; epidemiology; human papillomavirus vaccines; Pakistan

\section{Introduction}

Invasive cervical cancer (ICC) is the fourth most common cancer and the fourth leading cause of cancer related deaths amongst women worldwide, with nearly $85 \%$ of the global burden occurring in developing countries [1].

Human papillomavirus (HPV) infection is recognized as one of the major causes of infection-related cancers worldwide and represents an important global public health problem [2]. 
HPV infection is a sexually transmitted infection commonly found in the anogenital tract of men and women with and without clinical lesions, with peak prevalence in young sexually active individuals. The vast majority (70\%-90\%) of HPV infections is asymptomatic and resolve spontaneously in 1-2 years [3]. Persistent HPV infection is a well-established cause of ICC with HPV virtually causing $100 \%$ of squamous cell carcinoma (SCC) cases and more than $85 \%$ of adenocarcinoma (ADC) cases [3-5]. The vast majority of HPV-related cancers are ICC cases (more than 85\%), but HPV is also aetiologically linked with variable fractions of other anogenital cancers (anus, vulva, vagina and penis) and head and neck cancers (particularly the oropharynx), and it is also the causal factor in genital warts and recurrent respiratory papillomatosis [2]. More than 200 different HPV subtypes exist; more than 40 infect the genital tract, and of these 12 are classified as carcinogenic [3-5]. Data confirm HPVs16/18/45/33/31/52/58/35, in decreasing rank order, as the eight most frequently detected types in ICC, contributing to more than $90 \%$ of ICC globally [6-8].

Pakistan is currently the 6th most populous country in the world with 92 million women in 2015. This figure is expected to increase to up to 151 million by 2050 [9]. The magnitude of cervical cancer is difficult to estimate in the country because national cancer registries are lacking and the ones that exist only cover certain urban areas. Cervical cancer remains the 3rd leading cause of female cancer, and the 3rd cause of female cancer deaths in Pakistan. In 2012, there were an estimated 5233 new cases and 2876 ICC deaths, with incidence and mortality rates of 5.9 and 3.2 per 100,000; that are expected to rise. ICC is also the 2 nd most common cancer and the 5 th leading cause of cancer deaths in women aged 15 to 44 years [1].

The role of HPV infection in cervical cancer in the Pakistani population has not been broadly studied. Few studies have been done, and they provide little evidence, due to the small sample size, lack of consistency in results, and patchy representation of the country [10-14]. In addition, these studies have focused largely on Southern regions and specifically in the city of Karachi. Only a recent study has explored HPV infection in the North of Pakistan, where most of the population is living. The rates of high risk (HR) HPV infection obtained in these studies are provided in Table 1.

Being a lower-middle income country with a high burden of cancer, Pakistan lacks an effective nationwide screening and HPV vaccination program for ICC and most women are diagnosed of cancer at a late stage, when the survival rates are low. In Pakistan, there is only limited opportunistic screening, which is mostly based on visual inspection using acetic acid (VIA) $[11,15,16]$. Countries with resource constraints, like Pakistan, often lack personnel with technical expertise and public health infrastructure to provide Papanicolaou smear and cervical cytology [17]. HPV testing is another cervical cancer screening option that provides a $30 \%-40 \%$ gain in sensitivity for detecting cervical intraepithelial neoplasia (CIN) grade $2+$ compared to cytology at the cost of a 3\%-5\% lost in specificity, and allows safe extension of the intervals between screening episodes [18,19]. In addition, HPV testing technologies are exploring simpler and more accessible sampling devises and testing methods (such as "self-sampling") that can facilitate and increase participation in screening programs while reducing the cost and complexity. 
Table 1. Studies assessing human papillomavirus prevalence and type distribution in invasive cervical cancer in Pakistan.

\begin{tabular}{|c|c|c|c|c|c|c|c|c|c|}
\hline Reference & $\begin{array}{l}\text { Period of } \\
\text { Study }\end{array}$ & Cities & $\begin{array}{l}\text { Age } \\
\text { (Years) }\end{array}$ & PCR/Primers & Tested (N) & $\begin{array}{l}\text { Prevalence } \\
(\%, 95 \mathrm{CI})\end{array}$ & $\begin{array}{c}\text { Multiple } \\
\text { Infections (\%) }\end{array}$ & HPV Tested (RC\%) & $\begin{array}{c}\text { Details on } \\
\text { Histology }(\mathrm{N})\end{array}$ \\
\hline $\begin{array}{l}\text { Gul et al., } \\
2015 \text { [10] }\end{array}$ & 2010-2013 & $\begin{array}{l}\text { Islamabad, } \\
\text { Rawalpindi }\end{array}$ & $21-80$ & $\begin{array}{l}\text { GP5/GP6; TS16; } \\
\text { TS18; Beta globin }\end{array}$ & 56 & $\begin{array}{c}91.1 \\
(80.4-97.0)\end{array}$ & Not specified & $\begin{array}{l}\text { HPV16 (45.1\%). HPV18 } \\
\text { (43.1\%). other types }(11.8 \%)\end{array}$ & $\begin{array}{l}\text { SCC (33), } \\
\operatorname{ADC}(23)\end{array}$ \\
\hline $\begin{array}{l}\text { Siddiqa et al., } \\
2014 \text { [11] }\end{array}$ & 2007-2010 & Punjab & $25-70$ & $\begin{array}{l}\text { GP5+/GP6+; TS16; } \\
\text { TS18; C16E7; C18E7, } \\
\text { Beta globin }\end{array}$ & 47 & $\begin{array}{c}97.9 \\
(88.7-99.9)\end{array}$ & 34.0 & $\begin{array}{c}\text { HPV16 (32.6\%). HPV18 } \\
(28.3 \%) . \text { HPV1618 }(34.8 \%) \\
\text { other types }(4.3 \%)\end{array}$ & $\begin{array}{c}\text { SCC (43), ADC(1); } \\
\text { ADSC (3) }\end{array}$ \\
\hline $\begin{array}{l}\text { Raza et al., } \\
2010[12]\end{array}$ & 2004-2008 & Karachi & $15-59$ & $\begin{array}{l}\text { GP5+/6+; } \\
\text { Beta globin }\end{array}$ & 91 & $\begin{array}{c}91.2 \\
(83.4-96.1)\end{array}$ & 3.3 & $\begin{array}{c}\text { HPV16 (83.1\%). HPV18 (7.2\%). } \\
\text { HPV33 (1.2\%). HPV42 (1.2\%). } \\
\text { HPV45 (4.8\%). HPV56 (2.4\%). } \\
\text { HPV59 }(1.2 \%) . \text { HPV66 }(1.2 \%) . \\
\text { HPV69 }(1.2 \%)\end{array}$ & $\begin{array}{c}\text { SCC (79), } \\
\text { ADC (3), Small } \\
\text { cell (4), Other (5) }\end{array}$ \\
\hline $\begin{array}{c}\text { Yousuf et al., } \\
2010 \text { [13] }\end{array}$ & 2003-2008 & Karachi & $25-90$ & $\begin{array}{c}\text { My09/My11; } \\
\text { GP5+/6+ }\end{array}$ & 50 & $\begin{array}{c}18.0 \\
(8.6-31.4)\end{array}$ & Not specified & $\begin{array}{c}\text { HPV16 }(55.6 \%) . \\
\text { unknown }(44.4 \%)\end{array}$ & SCC (50) \\
\hline $\begin{array}{l}\text { Khan et al., } \\
2007[14]\end{array}$ & 1991-2005 & Karachi & $20-60$ & $\begin{array}{l}\text { GP5/GP6, TS16; } \\
\text { TS18; Beta globin }\end{array}$ & 60 & $\begin{array}{c}98.3 \\
(91.1-100)\end{array}$ & Not specified & $\begin{array}{c}\text { HPV16 (94.9\%). HPV18 }(1.7 \%) . \\
\text { other types }(3.4 \%)\end{array}$ & $\begin{array}{l}\text { SCC, } \operatorname{ADC}(\mathrm{N} \text { not } \\
\text { specified })\end{array}$ \\
\hline
\end{tabular}

HPV: Human papillomavirus; PCR: Polymerase Chain Reaction; N: Number; RC: Relative Contribution; SCC: squamous cell carcinoma; ADC: Adenocarcinoma;

ADSC: Adenosquamous carcinoma. Additional information: all studies used paraffin-embedded tissue samples [10-14] 
HPV prophylactic vaccines using virus like particles (VLP) have been recognized as an effective intervention to control cervical cancer and other HPV-related cancers in both men and women [20]. Recent recommendations from WHO suggest implementation of a coordinated and wide ranging strategy to prevent all HPV related disease including cervical cancer. Such programmes should target public education to increase awareness of risk factors for acquiring HPV infections, training of medical personnel on HPV screening techniques and improving information and access for screening, diagnosis and treatment of cervical cancer. Vaccination should be used as a primary prevention tool and should not undermine focus of national strategies for developing effective screening programmes since the HPV vaccine does not protect against all HPV types [20]. Currently available bivalent HPV vaccines-CervarixTM (2vHPV) (GlaxoSmithKline Biologicals, Rixensart, Belgium) - and quadrivalent HPV vaccine-Gardasil ${ }^{\circledR}$ (4vHPV) (Merck \& Co., Inc., Kenilworth, NJ, USA) - prevent HPVs16/18 infections, which account for almost $70 \%$ of ICC worldwide [7,8]. A novel broad spectrum 9-valent HPV vaccine-Gardasil ${ }^{\circledR} 9$ (9vHPV) conferring protection against five other common HPV types (HPVs31/33/45/52/58) has been recently approved [21,22]. All HPV vaccines also prevent other HPV-related cancers. WHO recommends the administration of HPV vaccines, if possible, before the onset of sexual activity, i.e., before first exposure to HPV infection [20]. Other potential primary prevention tools to avoid HPV infection include increased condom use, delay of age at first intercourse, and reduction in the number of sexual partners. These interventions have proven to be effective in reducing sexually transmitted infections and human immunodeficiency virus transmission, although their specific efficacy in terms of reducing cervical cancer incidence remains unknown [23].

Information on HPV genotype distributions is crucial for planning cervical cancer interventions. As mentioned, limited data is available in Pakistan, making it essential that further research be conducted on the burden of HPV-related cancers, HPV prevalence and type distribution in the general population of the country. This information would help to develop a comprehensive intervention policy, taking into account the religious and sociocultural aspects of the society for future management of cervical cancer [24]. Thus, the present study is aimed at providing baseline information about HPV prevalence and type distribution in the Pakistani population with ICC. This information is crucial for stakeholders to formulate the appropriate strategies toward cervical cancer prevention and control in the country.

\section{Results}

\subsection{General Characteristics}

Three-hundred-twenty-five formalin-fixed paraffin-embedded tissue blocks were consecutively selected from Shaukat Khanum Memorial Cancer Hospital and Research Centre (SKMCH \& RC), Lahore, Pakistan between 2005 and 2010. Histological evaluation confirmed 300 samples as cervical specimens, but three of them were dismissed because two were non-invasive tumours and one of the conventional SCC was of doubtful cervical origin. The remaining 25 samples were controls. The 297 ICC cases classified as suitable for HPV-DNA testing and a random sample of six controls was HPV-DNA analyzed (Figure 1). We excluded 17 samples negative for both HPV-DNA and tubulin. Consequently, the final analysis included 280 ICC samples with valid HPV-DNA results.

The mean age of the ICC cases at the time of diagnosis was 49.5 years (standard deviation-sd. 12.4). The majority of histological diagnoses were SCC (96.1\%; 95\%CI: 93.1-98.0), with two ADC and nine cases classified as other histological diagnoses. Invasion was higher than $50 \%$ in $65.7 \%$ (59.8-71.3) of the cases, and the presence of necrosis was less than $50 \%$ in $98.2 \%$ (95.9-99.4) of the cases. Ten cases $(3.6 \%)$ had a pre-neoplastic cervical intraepithelial neoplasia (CIN) grade 3 adjacent to the neoplastic lesion (Table 2). 


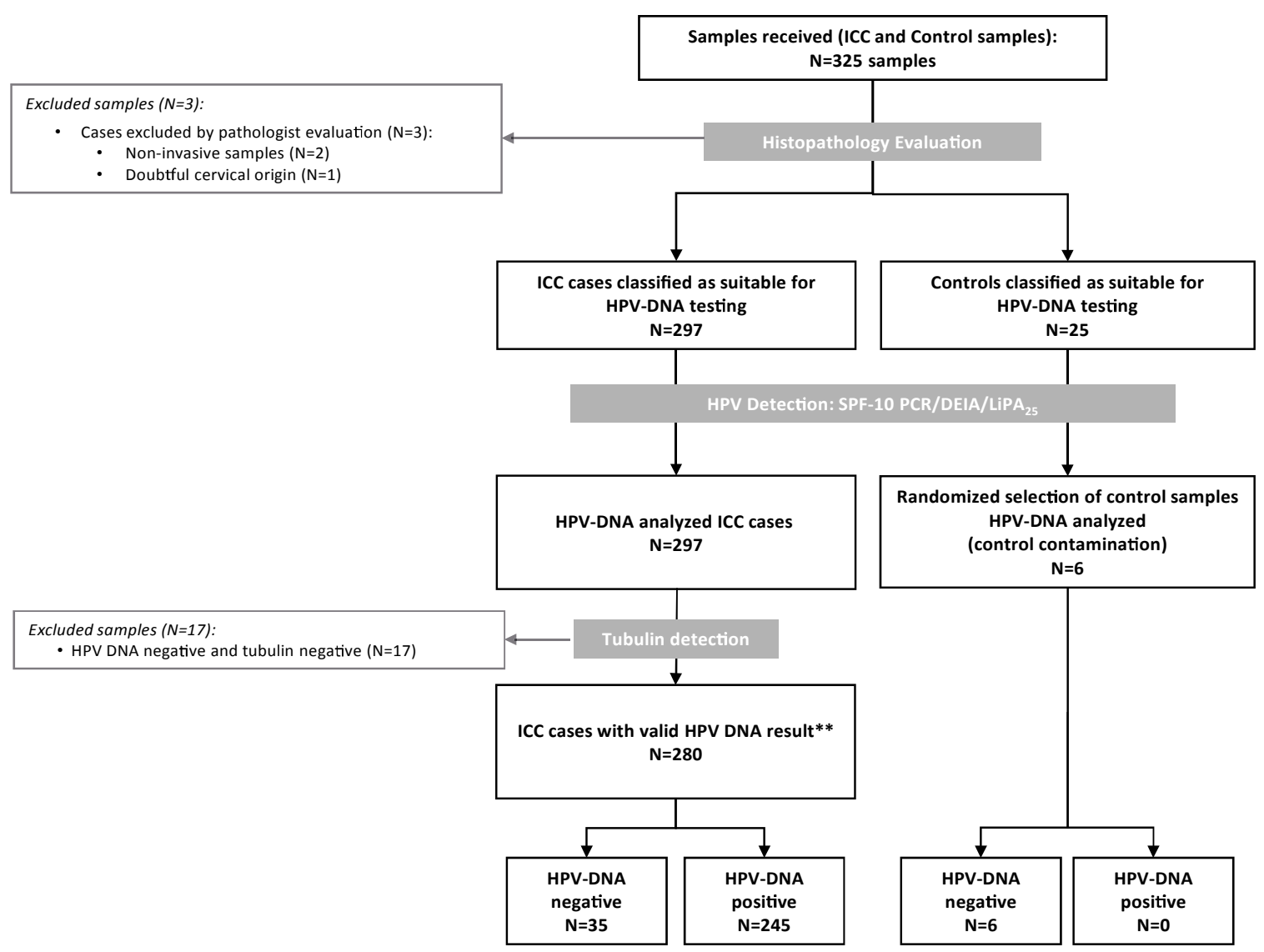

Figure 1. Algorithm of the inclusion criteria of the Pakistan invasive cervical cancer cases in the study. HPV: Human Papillomavirus; ICC: Invasive Cervical Cancer; ${ }^{* *}$ Valid cases: those that tested HPV-DNA positive or HPV-DNA negative with a positive tubulin result.

Table 2. Characteristics of the invasive cervical cancer cases from Pakistan and HPV-DNA prevalence.

\begin{tabular}{|c|c|c|c|c|c|}
\hline \multirow[b]{2}{*}{ Characteristics } & \multicolumn{2}{|c|}{ ICC Cases } & \multicolumn{2}{|c|}{ HPV-DNA Prevalence } & \multirow{2}{*}{$\begin{array}{c}\text { Chi-Squared/Fisher's } \\
\text { Exact Test } \\
p \text {-value }\end{array}$} \\
\hline & $\mathbf{N}$ & $\%^{a}$ & $\mathbf{N +}$ & $\% b$ & \\
\hline \multicolumn{6}{|l|}{ Age at diagnosis } \\
\hline Mean (Sd.) & \multicolumn{2}{|l|}{$49.5(12.4)$} & \multicolumn{2}{|c|}{ HPV-DNA +: 49.5 (12.5) } & \\
\hline \multicolumn{6}{|l|}{ Year of diagnosis } \\
\hline 2005 & 44 & 15.7 & 38 & 86.4 & \\
\hline 2006 & 51 & 18.2 & 41 & 80.4 & \\
\hline 2007 & 53 & 18.9 & 46 & 86.8 & \\
\hline 2008 & 47 & 16.8 & 44 & 93.6 & \\
\hline 2009 & 26 & 9.3 & 24 & 92.3 & 0.500 \\
\hline 2010 & 59 & 21.1 & 52 & 88.1 & $0.246 \#$ \\
\hline \multicolumn{6}{|l|}{ Histological evaluation } \\
\hline Squamous cell carcinoma & 269 & 96.1 & 236 & 87.7 & \\
\hline Adenocarcinoma & 2 & 0.7 & 1 & 50.0 & \\
\hline Other diagnosis: & 9 & 3.2 & 8 & 88.9 & 0.304 \\
\hline Undifferentiated carcinoma & 4 & 44.4 & 3 & 75.0 & \\
\hline \multirow{2}{*}{$\begin{array}{l}\text { Neuroendocrine carcinoma } \\
\text { Lymphoepithelioma-like } \\
\text { carcinoma }\end{array}$} & 3 & 33.3 & 3 & 100.0 & \\
\hline & 1 & 11.1 & 1 & 100.0 & \\
\hline Trophoblastic carcinoma & 1 & 11.1 & 1 & 100.0 & \\
\hline
\end{tabular}


Table 2. Cont.

\begin{tabular}{|c|c|c|c|c|c|}
\hline \multirow{2}{*}{$\%$ invasion } & \multicolumn{2}{|c|}{ ICC Cases } & \multicolumn{2}{|c|}{ HPV-DNA Prevalence } & $\begin{array}{c}\text { Chi-Squared/Fisher's } \\
\text { Exact Test }\end{array}$ \\
\hline & \multirow[b]{2}{*}{96} & \multirow[b]{2}{*}{34.3} & \multirow[b]{2}{*}{84} & \multirow[b]{2}{*}{87.5} & \multirow[b]{3}{*}{1.000} \\
\hline$\leqslant 50 \%$ & & & & & \\
\hline$>50 \%$ & 184 & 65.7 & 161 & 87.5 & \\
\hline \multicolumn{6}{|l|}{$\%$ necrosis } \\
\hline$\leqslant 50 \%$ & 275 & 98.2 & 242 & 88.0 & \multirow[b]{2}{*}{0.119} \\
\hline$>50 \%$ & 5 & 1.8 & 3 & 60.0 & \\
\hline \multicolumn{6}{|c|}{$\begin{array}{l}\text { Presence of pre-neoplastic } \\
\text { lesions adjacent to the } \\
\text { neoplastic lesion }\end{array}$} \\
\hline No & 270 & 96.4 & 235 & 87.0 & \multirow{3}{*}{0.619} \\
\hline CIN3 & 10 & 3.6 & 10 & 100.0 & \\
\hline Total & 280 & 100.0 & 245 & 87.5 & \\
\hline
\end{tabular}

ICC: Invasive cervical cancer; Sd.: Standard deviation; HPV: Human papillomavirus; N: Number of ICC cases; $\mathrm{N}+$ : number of ICC cases positives for HPV-DNA; CIN: cervical intraepithelial neoplasia; \#: trend test $p$-value.

a Column percentages: distribution of the cases for each variable. ${ }^{b}$ Row percentages: HPV positivity for each variable.

\subsection{HPV Prevalence and Type Distribution}

HPV-DNA prevalence was 87.5\% (83.0-91.1) (Table 2). Among HPV-DNA positive ICC, most of the cases presented as single infections (95.9\%) and only two cases harbored more than one HPV type $(0.8 \%)$ (Table 3). In eight cases, HPV-DNA was identified by DNA Enzyme Immunoassay (DEIA), but LiPA25 was negative and were finally classified as HPV undetermined (HPVX). Type specific distribution among HPV positive cases is described in Table 2. HPV16 was the most detected type, with $67.3 \%$ (61.1-73.2) relative contribution (RC) as single infection. HPV18 and HPV45 were the following most frequently detected types, with RCs of $10.2 \%$ (6.7-14.7) and 7.3\% (4.4-11.4), respectively. No low risk (LR) HPV types were identified.

Table 3. Human papillomavirus type distribution among HPV-DNA positive cases of invasive cervical cancer from Pakistan.

\begin{tabular}{ccc}
\hline \multirow{2}{*}{ HPV Type } & \multicolumn{2}{c}{ ICC Cases } \\
\cline { 2 - 3 } & N-Positive & RC (\%) \\
\hline Single HPV infections & 235 & 95.9 \\
HPV16 & 165 & 67.3 \\
HPV18 & 25 & 10.2 \\
HPV45 & 18 & 7.3 \\
HPV56 & 5 & 2.0 \\
HPV680r73 & 5 & 2.0 \\
HPV31 & 3 & 1.2 \\
HPV52 & 3 & 1.2 \\
HPV33 & 2 & 0.8 \\
HPV35 & 2 & 0.8 \\
HPV39 & 2 & 0.8 \\
HPV59 & 2 & 0.8 \\
HPV66 & 2 & 0.7 \\
HPV58 & 1 & 0.4 \\
Multiple HPV infections & 2 & $\mathbf{0 . 8}$ \\
HPV16 \& HPV18 & 1 & 0.4 \\
HPV16 \& HPV45 & 1 & 0.4 \\
HPVX & 8 & $\mathbf{3 . 3}$ \\
Total & $\mathbf{2 4 5}$ & $\mathbf{1 0 0 . 0}$ \\
\hline
\end{tabular}

ICC: Invasive cervical cancer; N-positive: Number of ICC cases HPV positive; RC: relative contribution; HPV: Human papillomavirus; HPVX: Undetermined type. 
When multiple infections were added to single types in accordance with a proportional weighting attribution, the overall contribution of HR types target by $2 \mathrm{vHPV}$ and $4 \mathrm{vHPV}$ vaccines (HPVs16/18) were 78.4\% (72.7-83.3); increasing up to 89.4\% (84.8-92.9) with the five additional types (HPVs31/33/45/52/58) included in the 9vHPV vaccine (Figure 2). Compared to data from broader geographical areas extracted from De Sanjose et al. [7], the contribution of HPVs16/18 was higher in Pakistan than in the Asian region or worldwide (single and multiple infections combined were $78.4 \%$ vs. $71.6 \%$ and $70.8 \%$, respectively; $p=0.029)$ but lower for HPV31/33/45/52/58 (11.1\% vs. $19.7 \%$ and $18.5 \%$, respectively; $p=0.003$ ). The RC increased up to $89.4 \%, 91.4 \%$ and $89.3 \%$, when combining the seven HR HPV types included in the 9vHPV vaccine and the differences among Pakistan, Asia and worldwide became minimal and not statistically significant.

Mean age of cases infected with HPV16 was 50.5 years old (48.6-52.4). Cases infected with HPV18 were 7 years younger than HPV16, mean age 43.3 (38.4-48.2) (ANOVA test $p$-value $=0.008)$. Similarly, HPV45 positive cases were six years younger than HPV16, mean age $44.4(40.8-47.9)(p=0.004)$. Mean age of cases infected with HPV types different to HPV16/18/45 was 52.3 (46.7-57.9) (Figure 3) (Supplementary Materials: Table S1).

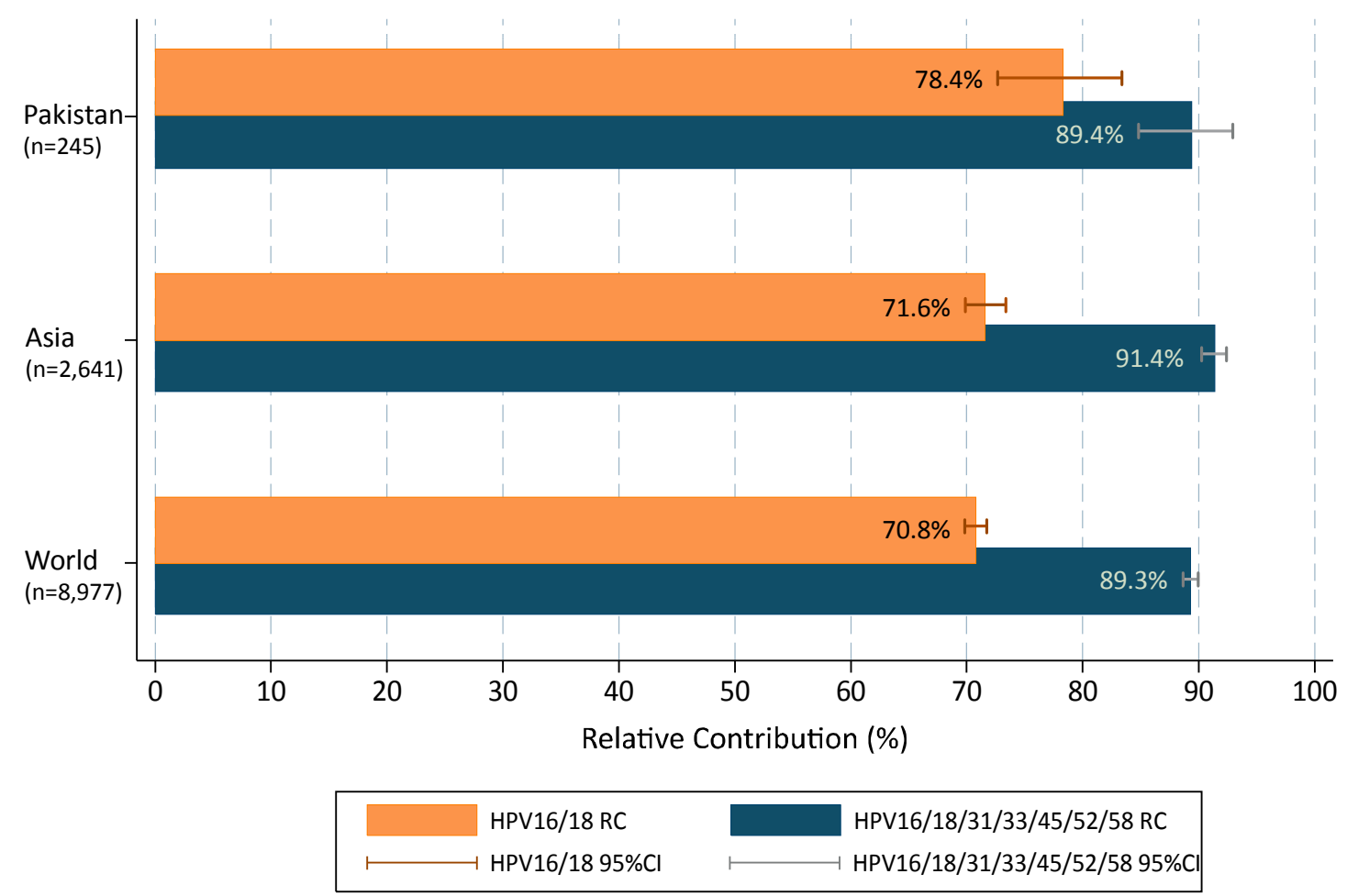

Figure 2. HPV type relative contribution in invasive cervical cancer cases from Pakistan positive for HPV, compared to Asia and Worldwide. 95\%CI: 95\% confidence interval. Additional information: multiple infections are computed according to a proportional weighting attribution $[25,26]$.

Without changes in prevention and control in Pakistan, and only due to population growth, projected global estimates of ICC cases attributable to HPV16/18 are expected to rise from 4250 in 2015 to 6998 new cases in 2050 and from 596 to 982 new cases attributable to HPV 31/33/45/52/58. 


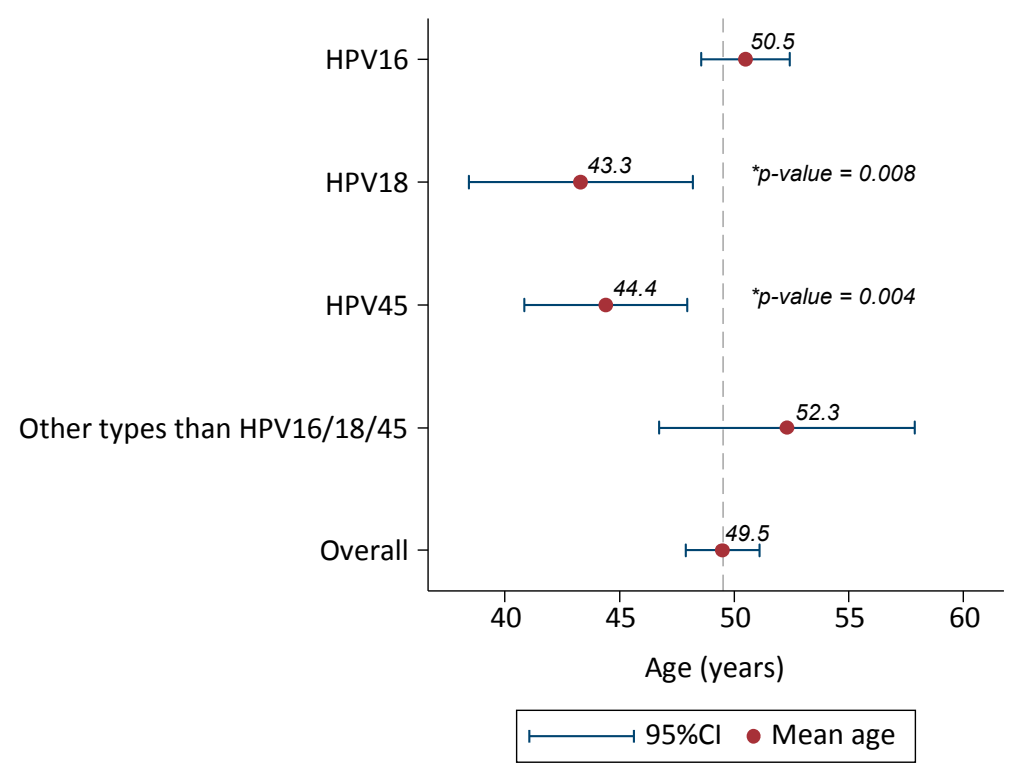

Figure 3. Mean age and $95 \% \mathrm{CI}$ of HPV-positive invasive cervical cancer cases from Pakistan (only single HPV infections considered). 95\% CI: 95\% confidence interval. Additional information: Comparison of mean age by HPV types (HPV16 reference category) with ANOVA test. $p$-Value statistically significant for HPV18 and HPV45.

\section{Discussion}

Data on type specific HPV infection in normal women and in women with cervical lesions is essential for assessing the potential impact of HPV vaccination and HPV testing for cervical cancer screening. The role of HPV infection in ICC is limited in Pakistan. To the best of our knowledge, this is the largest study reporting specifically on HPV prevalence and genotype distribution in women with ICC in Pakistan. The cases belong to an international study using standardized protocols and centralized HPV testing technology [7].

HPV prevalence in evaluable cases was $87.5 \%$ in our study. Data on overall HPV prevalence in ICC from Pakistan shows some variability, ranging from 18\% to 98\% [10-14] (Table 1). Since it is generally accepted that HPV virtually causes $100 \%$ of SCC ICC cases, the contrasting results could be partly explained by differences in the sensitivity of the HPV detection techniques used, the different histologies of the cases included in each study and the quality of the biological specimen, among others. In the present study, ICC cases HPV DNA negative were subject to polymerase chain reaction (PCR) targeting the human tubulin to evaluate the quality of DNA. Seventeen samples were both negative for HPV DNA and tubulin and therefore excluded for the final analyses.

Our data supported HPV16 as the most common type in Pakistan $(67.3 \%$ as single infection among HPV-DNA positive ICC cases), followed by HPV18 (10.2\%). These results are in agreement with the international data [6,7], but differences are noted when comparing with figures from local studies [10-14] (Table 1). This can be a consequence due to differences in techniques used for HPV detection, but also to the study setting and the specific characteristics of the population included (age, histology of the samples included ... etc.).

The third most common detected type in our study was HPV45, as it was already observed worldwide and in most world regions, including Western/Central Asia. Regional variation in the ranking of other HPV subtypes (HPV33, HPV52, HPV58) has been already noted in Asia, with higher contribution of HPV52 and 58 in Eastern Asia compared to Western/Central Asia countries [6,7,27].

HPV16 cases were older compared to HPV18 or HPV45 ones, mean age: 50.5, 43.3 and 44.4 years, respectively. Our results are in accordance with world estimates and suggest a rapid progression to ICC of HPV18/45 [7,28]. 
Multiple HPV infections were very low (0.8\%), with one case co-infected with HPV16/18 and other with HPV16/45. While some studies from Pakistan show similar low rates of co-infection a recent study conducted in Punjab registered higher rates of HPV16/18 co-infection $(34.0 \%)$ [11,12]. The use of different primers for HPV-DNA detection can explain the differences in the sensitivity to detect HPV infections.

Conventional squamous cell carcinoma was the commonest (96.1\%) histological type. The histopathological distribution is similar to previous studies from Pakistan [11,29].

The present study strengthens the knowledge of HPV prevalence and type distribution in cervical cancer cases in Pakistan. Although current incidence rates of ICC in Pakistan (5.9 per 100,000) are lower than world ones, ICC remains the third leading cause of female malignancies in the country. Pakistan is a more conservative culture, resulting in a lower prevalence of HPV and other sexual transmitted infections [16]. However, current changes in sexual behavior including increasing pre-marital sexual activity can lead to changes in HPV infection, and ICC rates are expected to increase [1,30]. A National Health program for cervical cancer screening, prevention and control is needed. For Pakistan, a lower middle income country, low cost options for screening and awareness of cervical cancer etiology can be used effectively to cover the masses. Nevertheless, HPV vaccines can play a vital role despite economic and cultural issues. Cost-effectiveness analyses in developing countries indicate that HPV vaccinations supplemented with screening may be a cost-effective strategy to reduce incidence and mortality by cervical cancer. However, concerns about affordability still remain for low income countries [31]. Pakistan is qualified for GAVI support (Global Alliance for Vaccines and Immunization), and could access the vaccine at a much better price. Demonstration programmes launched in several countries suggest that GAVI supported HPV programmes are successfully demonstrating the feasibility of vaccinating adolescent girls with reported $60 \%-90 \%$ coverage rates [32]. Hence, both the affordability and value for money of HPV vaccine will need to be favourable, as it will compete with money being spent on other existing national immunization initiatives [31].

The findings observed in the present study reveal that currently licensed $2 \mathrm{vHPV}$ and $4 \mathrm{vHPV}$ vaccines may potentially prevent close to $78 \%$ of the ICC cases in Pakistan. We have also tried to estimate the burden of cases prevented by cross protection of the 2vHPV and 4vHPV vaccines for Pakistan, Asia and the world. Cross protection efficacy data have been obtained from FUTURE I/II and PATRICIA clinical trials, as these studies had much the same length of follow-up [33,34]. We have used the information provided by the trials about the efficacy of the $2 \mathrm{vHPV}$ and $4 \mathrm{vHPV}$ vaccine against CIN2+ due to non HPV vaccine types and by including lesions co-infected with HPV16 or HPV18, in women who were HPV-naive at baseline. When taking into account the potential cross-protection conferred by the $2 \mathrm{vHPV}$ and 4vHPV vaccines against types not targeted by those vaccines, up to $9.9 \%$ and $5.1 \%$ cases could be additionally prevented by the $2 \mathrm{vHPV}$ and $4 \mathrm{vHPV}$ vaccines, respectively $[33,34]$. Comparatively, up to $14.4 \%$ and $8.0 \%$ cases could be additionally prevented by cross protection of 2 vHPV and 4vHPV vaccines in Asia and up to $14.5 \%$ and $8.6 \%$ worldwide, respectively (Table 4). Hence, these data should be taken with caution as the inclusion of lesions co-infected with HPV16/18 may overestimate the vaccine efficacy against lesions caused by non-vaccine types because co-infected lesions are more common in control groups than vaccine groups [33-35]. Finally, the addition of HPVs $31 / 33 / 45 / 52 / 58$ in the $9 v$ HPV vaccine could potentially prevent almost $90 \%$ of ICC lesions in Pakistan, similar to worldwide data [7] (Table 4). 
Table 4. Potential impact of licensed human papillomavirus vaccines to prevent invasive cervical cancer cases in Pakistan, compared to Asia and Worldwide.

\begin{tabular}{|c|c|c|c|c|c|c|c|c|c|}
\hline \multirow{2}{*}{$\begin{array}{l}\text { HPV Types of ICC Cases } \\
\text { Potentially Preventable } \\
\text { through Vaccination }\end{array}$} & \multicolumn{3}{|c|}{$\frac{\text { Pakistan }}{(N=300 ; N-p o s=245)}$} & \multicolumn{3}{|c|}{ Asia } & \multicolumn{3}{|c|}{ World } \\
\hline & N-pos & RC (\%) & $95 \%$ CI & N-pos & RC (\%) & $95 \%$ CI & N-pos & RC (\%) & $95 \% \mathrm{CI}$ \\
\hline $\begin{array}{l}\text { Cases infected with HPV } \\
\text { types targeted by } \\
\text { prophylactic vaccines } \\
\text { (HPV16/18) }\end{array}$ & 192 & 78.4 & $72.7-83.3$ & 1892 & 71.6 & $69.9-73.4$ & 6357 & 70.8 & $69.9-71.8$ \\
\hline $\begin{array}{l}\text { Cases infected with HPV } \\
\text { types non-targeted by } \\
\text { prophylactic vaccines } \\
\text { potentially preventable by } \\
\text { cross-protection conferred } \\
\text { by } 4 \mathrm{vHPV} \text { vaccine } \\
\text { (HPV31/33/35/39/45/ } \\
51 / 52 / 56 / 58 / 59) \text { (including } \\
\text { co-infection HPV16/18) }^{\text {b }}\end{array}$ & 12 & 5.1 & $2.6-8.4$ & 212 & 8 & $7.0-9.1$ & 736 & 8.2 & $7.6-8.8$ \\
\hline $\begin{array}{l}\text { Cases infected with HPV } \\
\text { types non-targeted by } \\
\text { prophylactic vaccines } \\
\text { potentially preventable by } \\
\text { cross-protection conferred } \\
\text { by } 2 \text { vHPV vaccine } \\
\text { (HPV31/33/35/39/45/51/ } \\
52 / 56 / 58 / 59 / 68)(\text { including } \\
\text { co-infection HPV16/18) }\end{array}$ & 24 & 9.9 & $6.4-14.2$ & 381 & 14.4 & $13.1-15.8$ & 1306 & 14.5 & $13.8-15.3$ \\
\hline $\begin{array}{l}\text { Cases infected with HPV } \\
\text { types targeted by } \\
\text { prophylactic } 9 \mathrm{vHPV} \text { vaccine } \\
(\text { HPV6/11/16/18/31/33/45/52/58) }\end{array}$ & 219 & 89.4 & $84.8-92.9$ & 2416 & 91.5 & $90.4-92.5$ & 8032 & 89.5 & $88.8-90.1$ \\
\hline
\end{tabular}

HPV: Human papillomavirus; ICC: Invasive cervical cancer; N: Number of ICC cases; N-positive: Number of ICC cases HPV positive; RC: Relative contribution; $95 \%$ CI: 95\% confidence interval. Additional information: Inclusion of HPV 16 and 18 co-infected lesions can overestimate cross protection efficacy of the vaccine against lesions with nonvaccine type HPVs, because co-infected lesions will be more common in control groups than vaccine groups. ${ }^{\mathbf{a}}$ Data obtained from De Sanjose et al. [7]. ${ }^{\mathbf{b}}$ Cross-protection conferred by $4 \mathrm{vHPV}$ vaccine for composites HPV31/33/35/39/45/51/52/56/58/59 (including co-infection HPV16/18) is estimated at $32.5 \%$ (95\%CI: 6.0-51.9) [33]. ${ }^{c}$ Cross-protection conferred by $2 \mathrm{vHPV}$ vaccine for composites HPV31/33/35/39/45/51/52/56/58/59/68 (including co-infection HPV16/18) is estimated at $56.2 \%$ (95\%CI: 37.2-65.0) [34].

\section{Materials and Methods}

\subsection{Study Design and Materials}

The present study is part of an international retrospective cross-sectional study to estimate the HPV DNA detection and genotype distribution in ICC lesions worldwide. The project was designed and coordinated by the Catalan Institute of Oncology (ICO), Barcelona, Spain and the DDL Diagnostic laboratory in Rijswijk, The Netherlands. An anonymized collection of formalin-fixed paraffin-embedded tissue blocks were subsequently selected from Shaukat Khanum Memorial Cancer Hospital and Research Centre, Lahore, Pakistan. In August 2013, 300 cervical cancer specimens were received. In addition, the center sent 25 paraffin blocks to be used as controls (containing non HPV-related specimens). Information about year of diagnosis, age at the time of diagnosis and original pathological diagnosis was also provided. Shaukat Khanum Memorial Cancer Hospital and Research Centre (SKMCH \& RC) is a tertiary cancer hospital and charitable institute. It has established itself as a center of excellence providing comprehensive care free to cancer patients irrespective of their ability to pay (about $75 \%$ patients get financial support); however, patients registered with us belong to diverse range of socio-economic strata and geographic areas. Nearly $74.6 \%$ belonged to the Province of Punjab (north of Pakistan) where $60 \%$ of the total population of the country lives, and SKMCH \& 
$\mathrm{RC}$ is situated in its provincial capital [36]. The ICC cases included in this study are a mix of patients getting treatment at $\mathrm{SKMCH} \& \mathrm{RC}$ and patients consulting for diagnostic purposes. All protocols were approved by the clinical research ethics committee of SKMCH \& RC.

\subsection{Pathology and Laboratory Procedures: Formalin Fixed Paraffin Embedded Blocks Processing, Histopathological Evaluation, HPV DNA Detection and Typing}

Paraffin blocks were processed under strict conditions. Pathology and laboratory procedures were performed at ICO as previously described [7]. Briefly, re-embedding of the tissue material was done if necessary when the paraffin block was in poor conditions for cutting. Microtome sectioning of the specimens under sterile conditions and sandwich technique were carried out to confirm an optimal number of sections to be used for pathology evaluation, DNA extraction, HPV-DNA detection, and HPV genotyping. At least four paraffin sections were obtained for each block (sandwich method). The first and last sections were stained with Hematoxylin and Eosin (H\&E) for histopathological evaluation and in between sections were used for HPV DNA testing. Histopathological evaluation included confirmation of ICC, histological type (squamous cell carcinoma, adenocarcinoma, adenosquamous carcinoma, other types), presence of pre-neoplastic lesions adjacent to ICC, degree of necrosis and of tumor infiltration (quantity of necrosis/infiltrating component of the tumor in the total of the section), and adequacy of the sample to proceed for HPV testing. A sample was determined adequate for HPV testing if ICC was observed in both the first and last stained sections. Cases difficult to classify, cases with a discordant diagnosis compared to the original diagnosis and all the rare histological types were further reviewed by two senior expert pathologists at ICO. Intermediate sections were used for HPV DNA detection and genotyping. DNA detection was performed by PCR with SPF-10 broad spectrum primers. The amplified PCR products were tested for the presence of HPV DNA using a DNA enzyme immunoassay (DEIA) that recognized at least 54 mucosal HPV genotypes. Borderline samples were run on the DEIA system again. Tubulin was used to evaluate the quality of DNA. All HPV DNA-negative samples in the study were subjected to a PCR targeting the human tubulin gene (forward primer: TCCTCCACTGGTACACAGGC; reverse primer: CATGTTGCTCTCAGCCTCGG), which generated a 65-bp amplicon, the same size as the SPF-10 amplicon used for assessing the presence of HPV DNA [37]. Samples that were both negative for HPV DNA and tubulin were excluded for the final analyses. Amplimers testing positive for viral DNA by DEIA were genotyped with a reverse hybridization line probe assay-LiPA25 that detects $25 \mathrm{HR}$ and LR types 6/11/16/18/31/33/34/35/39/40/42/43/44/45/51/52/53/54/56/58/59/66/68/70/74). The sequence variation within the SPF-10 interprimer region allows the recognition of these different HPV genotypes, but not types 68 and 73 because their interprimer regions are identical and cannot be distinguished with this test.

Control paraffin blocks were tissues unrelated to HPV that were processed at the same time as the cases. These controls were used to determine contamination during the inclusion process at the laboratory of origin.

\subsection{Statistical Analysis}

Variables included in the analysis were age at diagnosis, year of diagnosis, histopathological diagnosis, presence of non-neoplasic epithelium, presence of preneoplastic lesions (grade if any), presence of necrosis and tumor infiltration (as percentage of total), and HPV DNA detection and typing.

To compare HPV DNA positivity among variables, we used Pearson's chi-squared test or Fisher exact test when necessary. ANOVA test was performed to compare mean age among HPV DNA positive and negative. Evaluations of trends by age, year at diagnosis, percentage of necrosis and percentage of invasion were determined by trend test analysis for proportions. Statistically significant $p$-value was set at 0.05 .

HPV type-specific RC of the cases was also estimated. RC refers to the percentage of positive samples for a specific HPV type in relation to all the HPV-positive samples. HPV-type specific 
information for Pakistan only included single infections because only two specimens harbored multiple infections.

RC of HPV types included in current vaccines in Pakistan were compared to Asia and the world, using data from De Sanjose et al. [7]. For these comparisons, the contribution of multiple infections was also assessed. In cases with multiple infections, more than one specific HPV type was detected in the cervical lesion. However, it should be noted that each lesion is produced by one HPV type alone. For the present study, multiple infections were added to single types in accordance with a proportional weighting attribution where single HPV types were used as references. For example, if two cases with ICC lesions were found to test positive for both HPV 16 and 45, and there were nine cases infected by HPV-16 as a single type and one case infected by HPV 45 as a single type, then $[2 \times 9 /(9+1)]$ or 1.8 of these two multi-type infected lesions would be attributed to HPV 16 and $[2 \times 1 /(9+1)]$ or 0.2 attributed to HPV $45[25,26]$.

Estimation of new ICC cases potentially preventable by current HPV vaccines were calculated for the year 2015 and projected to year 2050, for Pakistan. Estimations were based on the following assumptions and data sources: (a) HPV virus is necessary for the development of ICC, so we assumed that the attributional fraction (AF) for each HPV type in ICC corresponded to the RC in CC; (b) Globocan 2012 incidence rates were used with the assumption that these rates will apply in the future. Globocan incidence rates were estimated as the weighted average of the local rates from South Karachi (1998-2002), Punjab, Lahore district (2008-2010) and Quetta (1998-1999) [1]; (c) the population forecast available in the latest World Population Prospects (revision 2015) was used [9]; and (d) impact of vaccination was not taken into account. Model-based predictions of long-term vaccine benefits are dependent on several uncertain assumptions and hence such weighted attributions should be interpreted with caution.

\section{Conclusions}

This study strengthens the knowledge of HPV prevalence and type distribution in ICC in Pakistan and highlights the importance of national level programmes for cervical cancer screening and control in the country. A high contribution of HR HPV types 16, 18 and 45 in cervical cancer cases in Pakistan is consistent with worldwide and regional data. Current HPV vaccines could potentially prevent $78.3 \%$ of ICC cases related to HPVs16/18 in Pakistan, increasing to almost $90 \%$ with the inclusion of HPVs31/33/45/52/58. Our data can help policy makers and public health professionals formulate the most appropriate strategies for cervical cancer prevention and control in the country. Further research is needed to collect data on screening and prevention strategies being used in the country and their potential impact on cervical cancer control.

Acknowledgments: The authors are grateful for the work of all of the ICO team, DDL Diagnostic Laboratory, the Steering Committee members and for the participation of all the collaborating centres for the RIS HPV TT (Retrospective International Survey in HPV Time Trends) study. The authors would like to specifically acknowledge the collaboration of "Shaukat Khanum Memorial Cancer Hospital and Research Centre" (Lahore, Pakistan). The RIS HPV TT study has received funds from Spanish public grants from the Instituto de Salud Carlos III (grants FIS PI030240, FIS PI061246, RCESP C03/09, RTICESP C03/10, RTIC RD06/0020/0095, RD12/0036/0056 and CIBERESP), from the Agència de Gestió d'Ajuts Universitaris i de Recerca AGAUR 2005SGR00695,2009SGR126, 2014SGR1077), from the Marató de TV3 Foundation (051530), from the Lilly Foundation (Premio de Investigación Biomédica Preclínica 2012 F. Xavier Bosch), and from Glaxo Smith Kline Biologicals. The founding sponsors had no role in the design of the study; in the collection, analyses, or interpretation of data; in the writing of the manuscript, and in the decision to publish the results.

Author Contributions: A.L., F.R., M.H., M.R., S.D.S., F.X.B., and L.A., and. participated in the study design, sample and data collection and analysis, interpretation of the results, and writing of the report. B.S., S.T., and O.C. participated in the analysis, interpretation of the results, and writing of the report. All authors provided approval of the final draft of the report.

Conflicts of Interest: S.T.: Institutional support: HPV vaccine trials and epidemiological studies were sponsored by GlaxoSmithKline (GSK), Merck and Sanofi Pasteur MSD. B.S. and L.A.: Institutional support: HPV vaccine trials and epidemiological studies were sponsored by GlaxoSmithKline, Merck and Sanofi Pasteur MSD. Personal support: Travel grants to scientific conferences were occasionally granted by Merck and Sanofi Pasteur MSD. F.X.B.: 
Institutional support: HPV vaccine trials and epidemiological studies were sponsored by GlaxoSmithKline, Merck and Sanofi Pasteur MSD, Qiagen and Roche. Personal support: Travel grants to conferences/symposia/meetings were occasionally granted by Glaxo Smith Kline, Merck, Sanofi Pasteur MSD, Roche or Qiagen. S.D.S.: Institutional support: HPV vaccine trials and epidemiological studies were sponsored by GlaxoSmithKline, Merck, Roche and Sanofi Pasteur MSD. Personal support: Travel grants to conferences/symposia/meetings were occasionally granted by GlaxoSmithKline, Sanofi Pasteur MSD or Qiagen. The authors from SKMCH \& RC have no financial conflict of interest in this study. None of the authors have received personal honoraria or payments from GSK for this study. M.H. and F.R. are currently involved in an ongoing clinical trial with GSK; however, they have not received any personal financial compensation for that clinical trial. A.L. and F.R. were invited for a lecture at a GSK organized event for expert talks; however, they have not received any payment for that. None of the authors from SKMCH \& RC have any other financial interests with the HPV vaccine manufacturers in the form of employment, consultancies, named positions on consultancy boards, stock ownership, honoraria, paid expert testimony, patents or patent applications, and travel grants.

\section{Abbreviations}

The following abbreviations are used in this manuscript:

$\begin{array}{ll}\text { ADC } & \text { Adenocarcinoma } \\ \text { ADSC } & \text { Adenosquamous carcinoma } \\ \text { AF } & \text { Attributional Fraction } \\ \text { CIN } & \text { Cervical Intraepithelial Neoplasia } \\ \text { DEIA } & \text { DNA Enzyme Immunoassay } \\ \text { H\&E } & \text { Hematoxylin and Eosin } \\ \text { HPV } & \text { Human Papillomavirus } \\ \text { HR } & \text { High Risk } \\ \text { ICC } & \text { Invasive Cervical Cancer } \\ \text { ICO } & \text { Institut Català d'Oncologia (Catalan Institute of Oncology) } \\ \text { LR } & \text { Low Risk } \\ \text { N } & \text { Number } \\ \text { PCR } & \text { Polymerase Chain Reaction } \\ \text { RC } & \text { Relative Contribution } \\ \text { SKMCH \& RC } & \text { Shaukat Khanum Memorial Cancer Hospital and Research Centre } \\ \text { SCC } & \text { Squamous Cell Carcinoma } \\ \text { Sd } & \text { Standard Deviation } \\ \text { VIA } & \text { Visual Inspection using Acetic acid } \\ \text { VLP } & \text { Virus Like Particles } \\ 2 v H P V & \text { bivalent HPV vaccine } \\ 4 v H P V & \text { quadrivalent HPV vaccine } \\ 9 v H P V & \text { ninevalent HPV vaccine } \\ 95 \% \text { CI } & \text { 95\% Confidence Interval }\end{array}$

\section{References}

1. Ferlay, J.; Soerjomataram, I.; Ervik, M.; Dikshit, R.; Eser, S.; Mathers, C.; Rebelo, M.; Parkin, D.M.; Forman, D.; Bray, F. GLOBOCAN 2012 v1.0, Cancer Incidence and Mortality Worldwide: IARC Cancer Base No. 11. International Agency for Research on Cancer: Lyon, France, 2013. Available online: http:/ /globocan.iarc.fr (accessed on 15 February 2016).

2. De Martel, C.; Ferlay, J.; Franceschi, S.; Vignat, J.; Bray, F.; Forman, D.; Plummer, M. Global burden of cancers attributable to infections in 2008: A review and synthetic analysis. Lancet Oncol. 2012, 13, 607-615. [CrossRef]

3. IARC. Monographs on the Evaluation of Carcinogenic Risks to Humans. A Review of Human Carcinogens. Part B: Biological Agents, Volume 100. International Agency for Research on Cancer: Lyon, France, 2011; Available online: http://monographs.iarc.fr/ENG/Monographs/vol100B/mono100B.pdf (accessed on 15 February 2016).

4. Castellsagué, X.; Díaz, M.; de Sanjosé, S.; Muñoz, N.; Herrero, R.; Franceschi, S.; Peeling, R.W.; Ashley, R.; Smith, J.S.; Snijders, P.J.F.; et al. Worldwide human papillomavirus etiology of cervical adenocarcinoma and its cofactors: Implications for screening and prevention. J. Natl. Cancer Inst. 2006, 98, 303-315.

5. Walboomers, J.M.; Jacobs, M.V.; Manos, M.M.; Bosch, F.X.; Kummer, J.A.; Shah, K.V.; Snijders, P.J.F.; Peto, J.; Meijer, C.J.L.M.; Muñoz, N. Human papillomavirus is a necessary cause of invasive cervical cancer worldwide. J. Pathol. 1999, 189, 12-19. [CrossRef] 
6. Li, N.; Franceschi, S.; Howell-Jones, R.; Snijders, P.J.F.; Clifford, G.M. Human papillomavirus type distribution in 30,848 invasive cervical cancers worldwide: Variation by geographical region, histological type and year of publication. Int. J. Cancer. 2011, 128, 927-935. [CrossRef] [PubMed]

7. De Sanjose, S.; Quint, W.G.; Alemany, L.; Geraets, D.T.; Klaustermeier, J.E.; Lloveras, B.; Tous, S.; Felix, A.; Bravo, L.E.; Shin, H.R.; et al. Human papillomavirus genotype attribution in invasive cervical cancer: A retrospective cross-sectional worldwide study. Lancet Oncol. 2010, 11, 1048-1056. [CrossRef]

8. Guan, P.; Howell-Jones, R.; Li, N.; Bruni, L.; de Sanjosé, S.; Franceschi, S.; Clifford, G.M. Human papillomavirus types in 115,789 HPV-positive women: A meta-analysis from cervical infection to cancer. Int. J. Cancer. 2012, 131, 2349-2359. [CrossRef] [PubMed]

9. United Nations: Department of Economic and Social Affairs, Population Division. World Population Prospects. 2015. The 2015 Revision. Available online: http://www.un.org/en/development/desa/ population/events/other/10/index.shtml (Accessed on 15 February 2016).

10. Gul, S.; Murad, S.; Javed, A. Prevalence of High risk Human Papillomavirus in cervical dysplasia and cancer samples from twin cities in Pakistan. Int. J. Infect. Dis. 2015, 34, 14-19. [CrossRef] [PubMed]

11. Siddiqa, A.; Zainab, M.; Qadri, I.; Bhatti, M.F.; Parish, J.L. Prevalence and genotyping of high risk human papillomavirus in cervical cancer samples from Punjab, Pakistan. Viruses 2014, 6, 2762-2777. [CrossRef] [PubMed]

12. Raza, S.A.; Franceschi, S.; Pallardy, S.; Malik, F.R.; Avan, B.I.; Zafar, A.; Pervez, S.; Serajuddaula, S.; Snijders, P.J.F.; van Kemenade, F.J.; et al. Human papillomavirus infection in women with and without cervical cancer in Karachi, Pakistan. Br. J. Cancer 2010, 102, 1657-1660. [CrossRef] [PubMed]

13. Yousuf, S.; Syed, S.; Moazzam, A.; Lucky, M.H. Frequency of high risk human papillomavirus types in squamous cell carcinoma of cervix among women. J. Pak. Med. Assoc. 2010, 60, 193-196. [PubMed]

14. Khan, S.; Jaffer, N.N.; Khan, M.N.; Rai, M.A.; Shafiq, M.; Ali, A.; Pervez, S.; Khan, N.; Aziz, A.; Ali, S.H. Human papillomavirus subtype 16 is common in Pakistani women with cervical carcinoma. Int. J. Infect. Dis. 2007, 11, 313-317. [CrossRef] [PubMed]

15. Sancho-Garnier, H.; Khazraji, Y.C.; Cherif, M.H.; Mahnane, A.; Hsairi, M.; El Shalakamy, A.; Osgulg, N.; Tuncerg, M.; Jumaanh, A.O.; Seoudi, M. Overview of cervical cancer screening practices in the extended Middle East and North Africa countries. Vaccine 2013, 31, G51-G57. [CrossRef] [PubMed]

16. Bruni, L.; Barrionuevo-Rosas, L.; Albero, G.; Aldea, M.; Serrano, B.; Valencia, S.; Brotons, M.; Mena, M.; Cosano, R.; Muñoz, J.; et al. Human Papillomavirus and Related Diseases in Pakistan, Summary Report 2015-12-23; ICO Information Centre on HPV and Cancer (HPV Information Centre): Barcelona, Spain, 2015.

17. Torre, L.A.; Bray, F.; Siegel, R.L.; Ferlay, J.; Lortet-Tieulent, J.; Jemal, A. Global cancer statistics, 2012. CA Cancer J. Clin. 2015, 65, 87-108. [CrossRef] [PubMed]

18. Ronco, G.; Dillner, J.; Elfström, K.M.; Tunesi, S.; Snijders, P.J.F.; Arbyn, M.; Kitchener, H.; Segnan, N.; Gilham, C.; Giorgi-Rossi, P.; et al. Efficacy of HPV-based screening for prevention of invasive cervical cancer: Follow-up of four European randomised controlled trials. Lancet 2014, 383, 524-532. [CrossRef]

19. Arbyn, M.; Ronco, G.; Anttila, A.; Meijer, C.J.L.M.; Poljak, M.; Ogilvie, G.; Koliopoulos, G.; Naucler, P.; Sankaranarayanan, R.; Peto, J. Evidence regarding human papillomavirus testing in secondary prevention of cervical cancer. Vaccine 2012, 30, F88-F99. [CrossRef] [PubMed]

20. World Health Organization (WHO). Human Papillomavirus Vaccines WHO Position Paper. World Health Organization: Geneva, Switzerland, 2014. Available online: http://www.who.int/wer/2014/wer8943.pdf? ua $=1$ (accessed on 15 February 2016).

21. Press Announcements-FDA approves Gardasil 9 for Prevention of Certain Cancers Caused by Five Additional Types of HPV. Available online: http://www.fda.gov/newsevents/newsroom/ pressannouncements/ucm426485.htm (accessed on 15 February 2016).

22. European Medicines Agency-News and Events-Gardasil 9 Offers Wider Protection against Cancers Caused by Human Papillomavirus (HPV). Available online: http://www.ema.europa.eu/ema/index. jsp?curl=pages/news_and_events/news/2015/03/news_detail_002295.jsp\&mid=WC0b01ac058004d5c1 (Accessed on 15 February 2016).

23. Shepherd, J.P.; Frampton, G.K.; Harris, P. Interventions for encouraging sexual behaviours intended to prevent cervical cancer. Cochrane Database Syst. Rev. 2011, 13, CD001035.

24. Badar, F.; Anwar, N. Vaccination against human papillomavirus for prevention of cervix uteri cancer in Pakistan-A public health perspective and debate. J. Ayub Med. Coll. Abbottabad. 2011, 23, 186. [PubMed] 
25. Insinga, R.P.; Liaw, K.L.; Johnson, L.G.; Madeleine, M.M. A systematic review of the prevalence and attribution of human papillomavirus types among cervical, vaginal, and vulvar precancers and cancers in the United States. Cancer Epidemiol. Biomarkers Prev. 2008, 17, 1611-1622. [CrossRef] [PubMed]

26. Wentzensen, N.; Schiffman, M.; Dunn, T.; Zuna, R.E.; Gold, M.A.; Allen, R.A.; Zhang, R.; Sherman, M.E.; Wacholder, S.; Walker, J.; et al. Multiple human papillomavirus genotype infections in cervical cancer progression in the study to understand cervical cancer early endpoints and determinants. Int. J. Cancer 2009, 125, 2151-2158. [CrossRef] [PubMed]

27. Serrano, B.; Alemany, L.; Tous, S.; Bruni, L.; Clifford, G.M.; Weiss, T.; Bosch, F.X.; de Sanjosé, S. Potential impact of a nine-valent vaccine in human papillomavirus related cervical disease. Infect. Agents Cancer 2012, 7, 38. [CrossRef] [PubMed]

28. Safaeian, M.; Schiffman, M.; Gage, J.; Solomon, D.; Wheeler, C.M.; Castle, P.E. Detection of precancerous cervical lesions is differential by human papillomavirus type. Cancer Res. 2009, 69, 3262-3266. [CrossRef] [PubMed]

29. Bhurgri, Y.; Nazir, K.; Shaheen, Y.; Usman, A.; Faridi, N.; Bhurgri, H.; Kayani, N.; Pervez, S.; Hasan, S.H.; Setna, F.; et al. Patho-epidemiology of Cancer Cervix in Karachi South. Asian Pac. J. Cancer Prev. 2007, 8, 357-362. [PubMed]

30. The DHS Program-Pakistan: DHS, 2012-13-Final Report (English). Available online: http://dhsprogram. com/publications/publication-fr290-dhs-final-reports.cfm (accessed on 15 February 2016).

31. Goldie, S.J.; O'Shea, M.; Diaz, M.; Kim, S.Y. Benefits, cost requirements and cost-effectiveness of the HPV16,18 vaccine for cervical cancer prevention in developing countries: Policy implications. Reprod. Health Matters 2008, 16, 86-96. [CrossRef]

32. Human Papillomavirus Vaccine Support-Gavi, the Vaccine Alliance. Available online: http://www.gavi. org/support/nvs/human-papillomavirus/ (accessed on 15 February 2016).

33. Brown, D.R.; Kjaer, S.K.; Sigurdsson, K.; Iversen, O.E.; Hernandez-Avila, M.; Wheeler, C.M.; Perez, G.; Koutsky, L.A.; Tay, E.H.; Garcia, P.; et al. The impact of quadrivalent human papillomavirus (HPV; types 6, 11, 16, and 18) L1 virus-like particle vaccine on infection and disease due to oncogenic non vaccine HPV types in generally HPV-naive women aged 16-26 years. J. Infect. Dis. 2009, 199, 926-935. [CrossRef] [PubMed]

34. Wheeler, C.M.; Castellsagué, X.; Garland, S.M.; Szarewski, A.; Paavonen, J.; Naud, P.; Salmerón, J.; Chow, S.N.; Apter, D.; Kitchener, H.; et al. Cross-protective efficacy of HPV-16/18 AS04-adjuvanted vaccine against cervical infection and precancer caused by non-vaccine oncogenic HPV types: 4-year end-of-study analysis of the randomised, double-blind PATRICIA trial. Lancet Oncol. 2012, 13, 100-110. [CrossRef]

35. Malagón, T.; Drolet, M.; Boily, M.C.; Franco, E.L.; Jit, M.; Brisson, J.; Brisson, M. Cross-protective efficacy of two human papillomavirus vaccines: A systematic review and meta-analysis. Lancet Infect. Dis. 2012, 12, 781-789. [CrossRef]

36. Mahmood, S.; Faraz, R.; Yousaf, A.; Asif, H.; Badar, F. Cancer Registry and Clinical Data Management (CRCDM)—Shaukat Khanum Memorial Cancer Hospital and Research Center (SKMCH \& RC)—Report Based on Cancer Cases Registered at SKMCH \& RC from December 1994-December 2014 and in 2014. Released June 2015. Available online: www.shaukatkhanum.org.pk (accessed on 15 May 2016).

37. Alemany, L.; Saunier, M.; Alvarado-Cabrero, I.; Quirós, B.; Salmeron, J.; Shin, H.R.; Pirog, E.C.; Guimerà, N.; Hernandez-Suarez, G.; Felix, A.; et al. Human papillomavirus DNA prevalence and type distribution in anal carcinomas worldwide. Int. J. Cancer 2015, 136, 98-107. [CrossRef] [PubMed]

(C) 2016 by the authors; licensee MDPI, Basel, Switzerland. This article is an open access article distributed under the terms and conditions of the Creative Commons Attribution (CC-BY) license (http:/ / creativecommons.org/licenses/by/4.0/). 